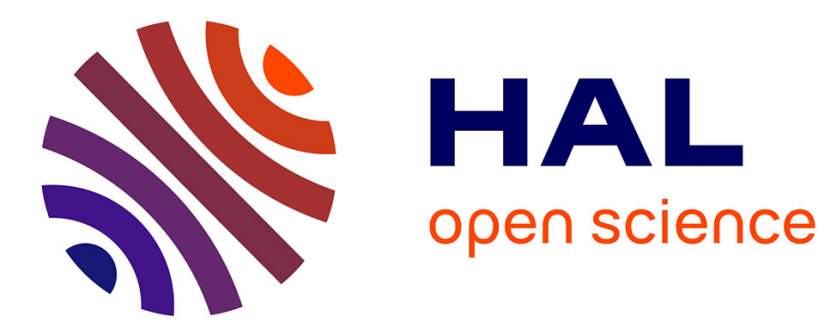

\title{
Deposition of Oxide Layers by Computer Controlled"Injection-LPCVD"
}

\author{
F. Felten, J. Senateur, F. Weiss, R. Madar, A. Abrutis
}

\section{To cite this version:}

F. Felten, J. Senateur, F. Weiss, R. Madar, A. Abrutis. Deposition of Oxide Layers by Computer Controlled"Injection-LPCVD". Journal de Physique IV Proceedings, 1995, 05 (C5), pp.C5-1079-C51086. 10.1051/jphyscol:19955127 . jpa-00253823

\section{HAL Id: jpa-00253823 https://hal.science/jpa-00253823}

Submitted on 1 Jan 1995

HAL is a multi-disciplinary open access archive for the deposit and dissemination of scientific research documents, whether they are published or not. The documents may come from teaching and research institutions in France or abroad, or from public or private research centers.
L'archive ouverte pluridisciplinaire HAL, est destinée au dépôt et à la diffusion de documents scientifiques de niveau recherche, publiés ou non, émanant des établissements d'enseignement et de recherche français ou étrangers, des laboratoires publics ou privés. 
JOURNAL DE PHYSIQUE IV

Colloque C5, supplément au Journal de Physique II, Volume 5, juin 1995

\title{
Deposition of Oxide Layers by Computer Controlled "Injection-LPCVD"
}

\author{
F. Felten, J.P. Senateur, F. Weiss, R. Madar and A. Abrutis* \\ Laboratoire des Matériaux et du Génie Physique, INPG, URA 1109 du CNRS, ENS de Physique de \\ Grenoble, BP. 46, 38402 Saint Martin d'Hères cedex, France \\ * Department of General and Inorganic Chemistry, Faculty of Chemistry, Vilnius University, 2734 Vilnius, \\ Lithuania
}

\begin{abstract}
A new process for stable generation of precursor's vapour pressure for CVD thin layers synthesis is experimented. The vapour pressure is controlled by sequential computer-driven injection of precise micro amounts of liquid in an evaporator, where flash volatilization occurs. During deposition, the precursors are maintained at room temperature under inert gases in an hermetically closed vessel : even thermally unstable precursors may be used. The results reported here are focused on the OMCVD deposition of Ta2 $\mathrm{O}_{5}$. The growth rate increases up to 11 $\mu \mathrm{m} / \mathrm{h}$ at $650^{\circ} \mathrm{C}$ (amorphous layers), and decreases above (crystallized layers). In a second part, we demonstrate the feasibility of $\mathrm{Ta}_{2} \mathrm{O}_{5} / \mathrm{SiO}_{2}$ multilayers using two injectors.
\end{abstract}

\section{INTRODUCTION}

The technological application of CVD requires the generation of highly stabilized vapour pressure of chemical compounds involving the elements which compose the layers. For some chemical elements, gaseous compounds at room temperature do not exist, which requires the heating of solid or liquid precursors inside the source, and heated lines and valves between the sources and the deposition zone. When the precursors are solids at the volatilization temperature, the sublimation rate strongly depends on the precursor's free surface inside the source: the vapour pressure cannot be stabilized, since it's related to the granulometry and to the quantity of precursors remaining inside the evaporator. For some elements with high technological interest (i.e. $\mathrm{Ba}$ ), the precursors actually known are thermally unstable at the sublimation temperature, and their thermal stability and volatility depends on the preparation procedure. The irreproducibility of the resulting vapour pressure leads to some spread in the properties of the layers obtained by CVD : for high temperature superconductors deposition, for instance, very high quality super conducting layers or S-I-S superlattices have been obtained by CVD, but the irreproducibility of the barium precursor's vapour pressure is a drastic problem for technological applications.

Different solutions have been tested by many laboratories to solve this problem [ 1 to 4$]$. All are based on the same principle : the precursors are kept in a closed vessel maintained at room temperature under inert gases, only small amounts are continuously or sequentially introduced inside the heated source zone, where they are volatilized. The main problem is the handling of precise micro amounts of precursors, especially when they are solid: the reproducibility of the introduction of micrograms of powders inside an evaporator is a very complex technological problem! Another possibility is the slow introduction inside the evaporator of a solid bar obtained by compacting a mixture of solid precursors [5], but a problem arises with the homogeneity of the bar. The handling of liquids is considerably easier, and many experiments are made with liquid precursors or solutions of liquid precursors in an organic solvent.

The new process presented here is based on the principle of computer-controlled injection of micro amounts of liquid droplets, now currently used for fuel injection in recent thermal motors. The droplets of liquid precursors (or of precursor's solution) are sequentially injected inside an evaporator, where they are "flash" volatilized. The evaporator being close to the deposition zone, the transfer time is very short, which enables high superheating, giving rise to very high precursor's vapour pressure and high deposition rates. On the other hand, with the use of little droplets volume and slow injection frequency, very low deposition rates are obtained, only by changing the computer's data input.

We present here the first results obtained with this technique. In order to check the performances of the system, the process has been tested on simple oxide layers, which can already be obtained by 
classical OMCVD processes [6-7-8]. In the second part, the deposition of $\mathrm{Ta}_{2} \mathrm{O}_{5} / \mathrm{SiO}_{2}$ multilayer by simply using two injectors shows the potential of this new process.

\section{EXPERIMENTAL}

The precursor's solution (or the pure liquid precursor) is contained in a hermetically closed vessel, pressurized under 1,5 Bar of pure nitrogen, connected to the injector, which is a high speed electro valve. The injector is connected to a furnace situated inside the reactor (evaporator - held at $200-300^{\circ} \mathrm{C}$ ). In our set of experiments, the pressure inside the reactor being $5 \mathrm{mBar}$, the droplets injected (precursor + solvent) are flash volatilized. A vector gas, flowing along the neck of the injector, drives the vapours toward the RF-heated substrate $\left(400-1000^{\circ} \mathrm{C}\right)$.

The flash volatilization of the droplets (some $\mu \mathrm{l}$ of liquid) inside the evaporator leads to a pulsed variation of pressure, depending on the opening time, the frequency of injection and also on the geometry of the reactor. Fig 1 and fig 2 represent the vertical shaped and the $U$ shaped reactor (internal volume respectively 1000 and $2000 \mathrm{~cm}^{3}$, distance evaporator-substrate respectively 4 and $70 \mathrm{~cm}$ and a volume of $300 \mathrm{~cm}^{3}$ for the evaporators), which have been used in the first set of experiments reported here.

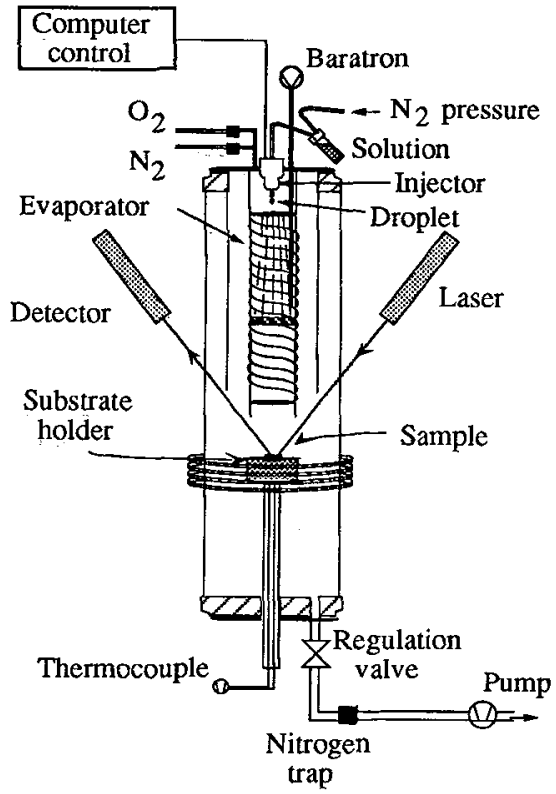

Figure 1 : Vertical shaped reactor

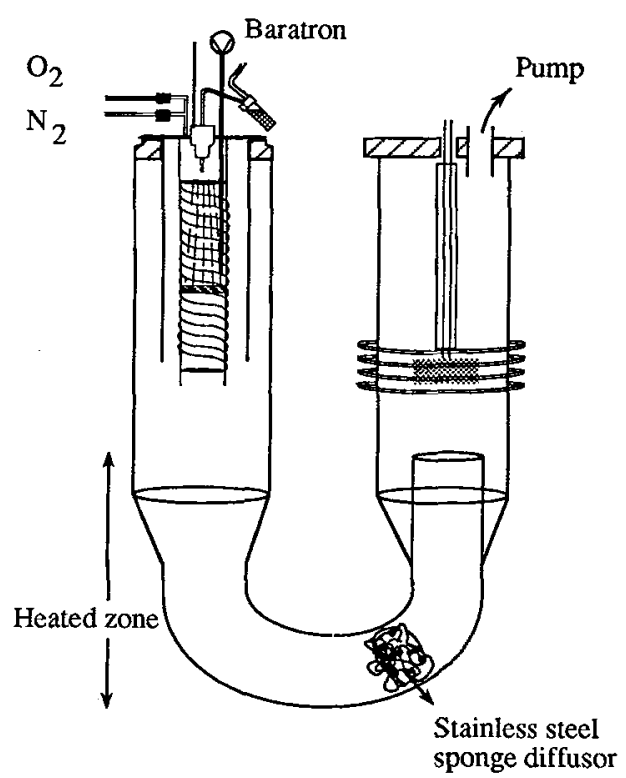

Figure 2: U shaped reactor

For the former, the evaporated zone is very close to the substrate holder as compared to the latter. The pressure variation at each injection is related indeed to the volume of the reactor, so this phenomenon is less important for the second version of reactor.

The pressure is measured inside the evaporator with a high accuracy pressure gauge (baratron) connected to a high speed plotter. Fig 3 shows the variations of pressure induced by the flash evaporation of the droplets. Opening time and frequency of injection define the partial pressure of precursor gas. With a high frequency of injection, the system experiences an average pressure. With a low injection frequency, the system experiences pressure pulses. In our experimental set-up, pressure is defined only by the vector gas flow and by a valve limiting the pump efficiency : the injection increases the pressure inside the reactor. When the injection is stopped, about 10 seconds are needed to retrieve the initial pressure in our $1000 \mathrm{~cm}^{3}$ reactor, with $50 \mathrm{sccm}$ gas flow. So for the deposition of multilayers, this time has to be considered to avoid the mixture of the different injected precursors. 


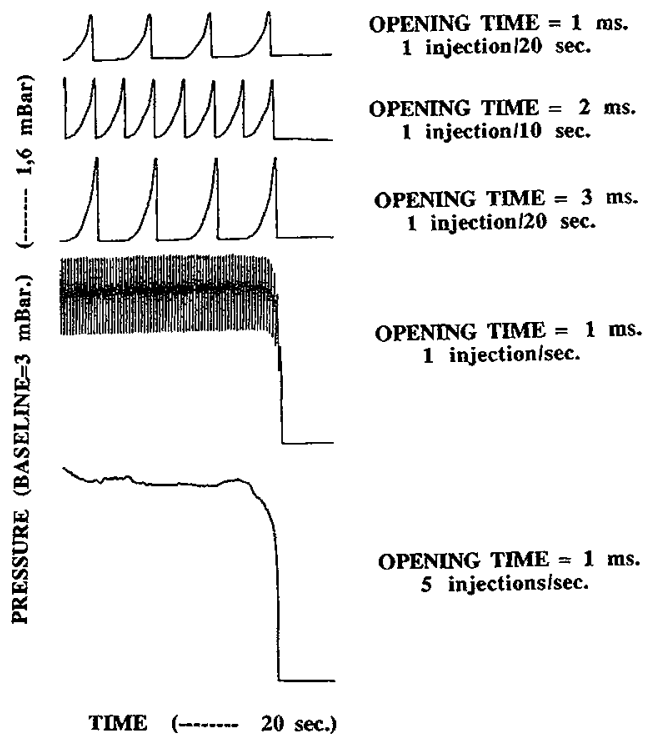

Figure 3 : Variation of pressure in the evaporator with different opening time and frequency of injection.

This new process presents two particularities : the presence of an organic solvent and the sequential injection of precursors.

The presence of the solvent in the reaction zone changes the chemical reaction, this can be favourable for the deposition [10] or can be a drawback, above all in the second version of the reactor (fig 2): the pressure pulses at each injection being little, the gas speed in the reaction chamber is low. Many kinds of solvents have been tested (Ethanol, methanol, tetrahydrofurane, ketones, hydrocarbides). Most of the precursors are moisture sensitive : hydrocarbides are very convenient solvents, since they did not mix with water. Most of the experiments reported here have been made with hexane. In the second version of the reactor, if inert gas is used as vector, the cracking of the hexane occurs at $\mathrm{T}>700^{\circ} \mathrm{C}$ giving rise to carbon deposition. As a consequence, the use of hexane $\left(\mathrm{C}_{6} \mathrm{H}_{6}\right)$ as solvent requires oxygen gas to burn carbon when the gas speed is low. Whereas in the first version of the reactor deposition of $\mathrm{Ta}_{2} \mathrm{O}_{5}$ is possible even though $\mathrm{N}_{2}$ is used as carrier gas, since the gas speed is high.

\subsection{Deposition of Tantalum pentoxide films}

$\mathrm{Ta}_{2} \mathrm{O}_{5}$ films offer a great interest for a large range of applications such as insulators in VLSI devices, electroluminescent devices and capacitors.

$\mathrm{Ta}_{2} \mathrm{O}_{5}$ films were deposited on Silicon $(100)$ substrates $(15 \times 15 \mathrm{~mm})$ using a solution of the $\mathrm{Ta}\left(\mathrm{OC}_{2} \mathrm{H}_{5}\right)_{5}$ precursor dissolved in two kinds of solvent (Tetrahydrofurane or hexane) with a concentration of $50 \mathrm{mg} / \mathrm{ml}$. The temperature of the evaporator was fixed at $200^{\circ} \mathrm{C}$. An injection of one droplet per second with an opening time of $2 \mathrm{~ms}$ was performed (deposition time $=300 \mathrm{~s}$ ). The droplets average volume over one deposition run was determined by weighing the CVD source before and after the experiment. Within this set of experiments the average volume of droplets ranges between $11.3 \mu \mathrm{l}$ and $11.8 \mu \mathrm{l}$ (accuracy of $\pm 2 \%$ ).

During deposition, the film thickness was measured in situ by reflectometry, using a $6700 \AA$ wavelength laser at $60^{\circ}$ incidence. After deposition, the layers were characterized by X-ray diffraction, Rutherford Backscattering (RBS), NRA analysis and Scanning Electron Microscopy (SEM). Refractive index and film thickness were measured by Ellipsometry : the results are well correlated with the reflectance spectras obtained with the in situ reflectometry measurements. 
The growth rate and the corresponding refractive index as a function of substrate temperature are shown on fig 4 . The refractive indices are in good agreement with the results obtained by Treichel $\mathrm{H}$. and al [7], but the growth rates are higher [6-7].

A maximum growth rate of about $11 \mu \mathrm{m} / \mathrm{h}$ is reached at $650^{\circ} \mathrm{C}$. Up to this temperature $\mathrm{Ta}_{2} \mathrm{O}_{5}$ films are amorphous, as can be seen on fig 5 . They crystallize as $\beta$ - $\mathrm{Ta}_{2} \mathrm{O}_{5}$ phase without any particular orientation.

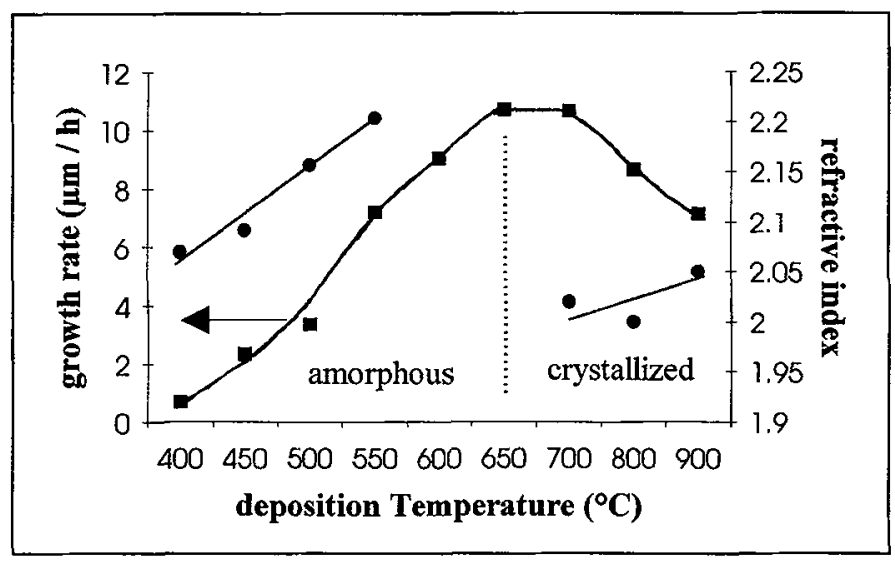

Figure 4: Growth rate and refractive index of $\mathrm{Ta}_{2} \mathrm{O}_{5}$ films as a function of deposition temperature. (Solvent:THF, Concentration $=50 \mathrm{mg} / \mathrm{ml}, \mathrm{P}=5 \mathrm{mb}, \mathrm{O}_{2} / \mathrm{N}_{2}=10 / 40 \mathrm{sccm}$ )

The refractive index of the $\mathrm{Ta}_{2} \mathrm{O}_{5+x}$ films depends strongly on the morphology of the films. Up to the deposition temperature limiting amorphous and crystallized phase, it increases steadily, probably in relation with an increasing densification of the layer. The lowering of refractive index for crystallized films is probably related to a lower densification of the films. Furthermore, this last point is underlined by the reflectance spectras on fig 6 . The absorption of laser light through the layer deposited at $800^{\circ} \mathrm{C}$ comes from the diffusion of the light at the grain boundaries. On the other hand, the decrease of light intensity is strongly lowered for amorphous layers.

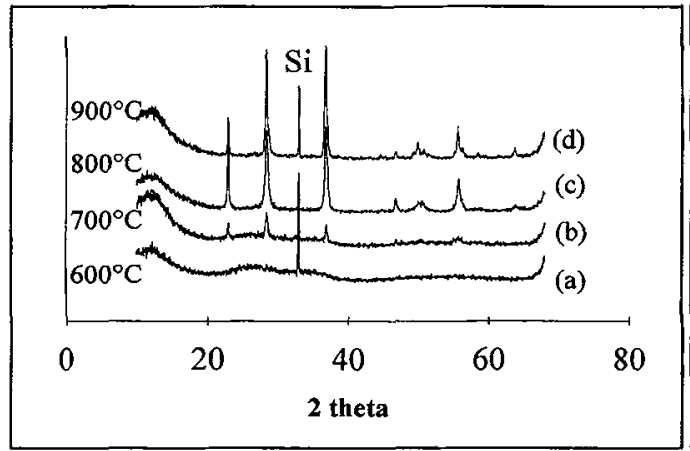

Figure 5: X-ray diffraction patterns of $\mathrm{Ta}_{2} \mathrm{O}_{5}$ films grown at different temperatures $\left(\lambda_{\mathrm{cu}}=0.15406 \mathrm{~nm}\right)$. (thicknesses (nm): (a) 280, (b) 755, (c) 720, (d) 595)

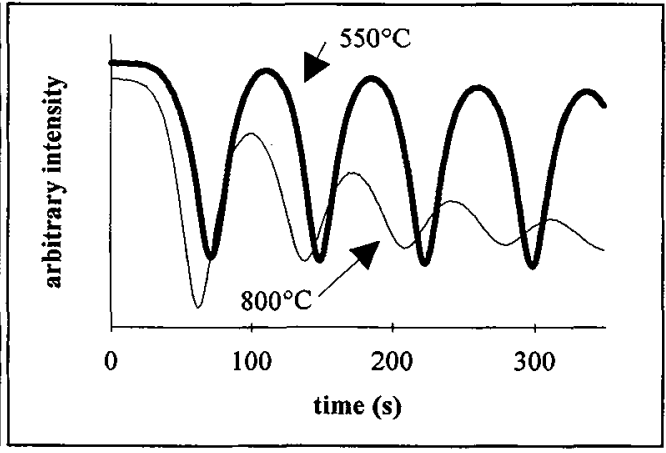

Figure 6: Laser reflectometry spectras of films deposited at $550^{\circ} \mathrm{C}$ and $800^{\circ} \mathrm{C}$. 
Fig 7 shows a SEM photograph of a cross-section of a Ta2 $\mathrm{O}_{5}$ film deposited at $850^{\circ} \mathrm{C}$ in the vertical reactor (solvent: hexane, $\mathrm{C}=30 \mathrm{mg} / \mathrm{ml}$, Pressure $=5 \mathrm{mb}, \mathrm{N}_{2}=50 \mathrm{sccm}$, volume of droplet $=2 \mu 1$, deposition time ${ }^{\prime} 6^{\prime}$ ). The layer's texture is composed by columnar grains. The surface of the film has a maximum roughness of about $50 \mathrm{~nm}$ depth (estimated from SEM photograph).

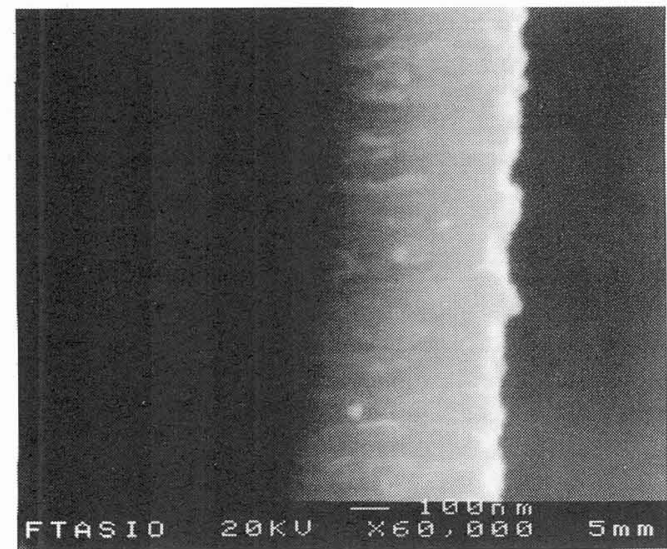

Figure 7: View of a cross-section of $\mathrm{Ta}_{2} \mathrm{O}_{5}$ deposited at $850^{\circ} \mathrm{C}$.

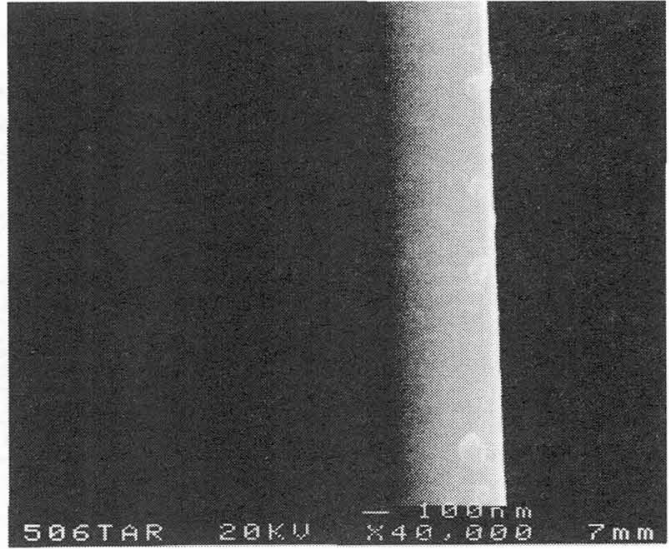

Figure 8: View of a cross-section of annealed film at $650^{\circ} \mathrm{C}$ under $\mathrm{Ar}$ for $20 \mathrm{hr}$.

Such a surface is not suitable for some applications like capacitors. To decrease surface roughness, investigations were made on amorphous layer deposited at $600^{\circ} \mathrm{C}$ (solvent: hexane, $\mathrm{C}=30 \mathrm{mg} / \mathrm{ml}$, Pressure $=5 \mathrm{mb}, \mathrm{N}_{2}=50 \mathrm{sccm}$, volume of droplet $=2 \mu$, deposition time $10^{\prime}$ ) which were subjected to exsitu annealing at 650 and $800^{\circ} \mathrm{C}$. Both surfaces (before and after annealing) are very smooth (fig 8). X-ray pattern on fig 9 shows a good crystallization with well defined peaks.

Moreover, thermal treatment leads to an improve in the refractive index. These values are listed in table1.

\begin{tabular}{|c|c|c|c|c|}
\hline Sample & $\begin{array}{c}\text { Temperature of } \\
\text { deposition }\end{array}$ & $\begin{array}{c}\text { Annealing } \\
\text { time }\end{array}$ & microstructure & $\begin{array}{c}\text { index of } \\
\text { refraction }\end{array}$ \\
\hline Ta-506 & $600^{\circ} \mathrm{C}$ & $0 \mathrm{~h}$ & amorphous & 2.160 \\
\hline Ta-506R & $\begin{array}{c}\text { Annealed at } \\
800^{\circ} \mathrm{C}\end{array}$ & $1 \mathrm{~h} 30$ & crystallized & 2.252 \\
\hline Ta-506RR & $\begin{array}{c}\text { Annealed at } \\
650^{\circ} \mathrm{C}\end{array}$ & $20 \mathrm{~h}$ & crystallized & 2.391 \\
\hline
\end{tabular}

Table 1: Refractive indices of $\mathrm{Ta}_{2} \mathrm{O}_{5}$ layers before and after annealing.

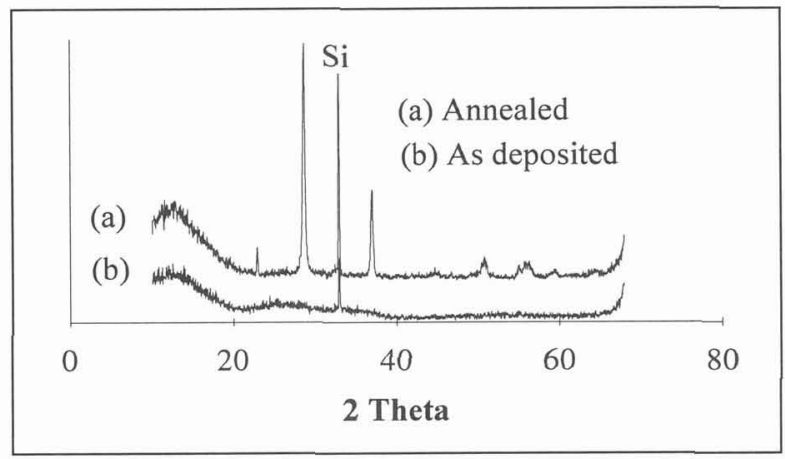

Figure 9: $\mathrm{X}$-ray patterns of as-deposited and annealed $\mathrm{Ta}_{2} \mathrm{O}_{5}$ films $\left(\lambda_{\mathrm{cu}}=0.15406 \mathrm{~nm}\right)$. 
Sample Ta-506R was annealed at $850^{\circ} \mathrm{C}$ for $1 \mathrm{~h} 30$ under Ar. Both annealed samples present high refractive index, similar to the bulk's value $(n=2.37)$, indicating a change in microstructure of the layer [8]. The best results are obtained when the temperature of annealing is lower, which requires long annealing time.

The analysis of film composition for carbon incorporation and stoichiometry was carried out by use of RBS/NRA method. The main purpose was to study the influence of the carrier gas on the film composition.

$\mathrm{Ta}_{2} \mathrm{O}_{5}$ films were deposited at $600^{\circ} \mathrm{C}$ in the vertical shaped reactor under a total pressure of $5 \mathrm{mb}$, using a solution of $\mathrm{Ta}(\mathrm{OEt}) 5(25 \mathrm{mg} . / \mathrm{ml})$ mixed with HDPM and hexane as solvent. HDPM is a chemical ligand which improves the deposition rate by changing precursor's chemistry. The results are reported in table 2 .

\begin{tabular}{|c|c|c|c|}
\hline sample & $\begin{array}{c}\text { carrier gas } \\
\text { (sccm) }\end{array}$ & $\begin{array}{c}\text { thickness } \\
\AA\end{array}$ & composition \\
\hline $\mathrm{Ta} 82$ & $\mathrm{O} 2=50$ & 3560 & $\mathrm{Ta} 2 \mathrm{O} 5.6 \mathrm{C} 0.2$ \\
\hline $\mathrm{Ta} 83$ & $\mathrm{O} 2=50$ & 3300 & $\mathrm{Ta} 2 \mathrm{O} 5.55 \mathrm{C} 0.58$ \\
\hline $\mathrm{Ta} 84$ & $\mathrm{~N} 2=50$ & 3520 & $\mathrm{Ta} 2 \mathrm{O} 5.08 \mathrm{C} 0.16$ \\
\hline
\end{tabular}

Table 2: Film composition and thickness of $\mathrm{Ta}_{2} \mathrm{O} 5$ oxide deposited at $600^{\circ} \mathrm{C}$ under $5 \mathrm{mb}$ total pressure.

The deposition conditions are summarized as follows : an injection of one droplet (volume of $4 \mu \mathrm{l}$ ) per second was performed. For the sample 83, a cyclic injection of 5 droplets was used with a dead time of 15 seconds between each sequence.

It seems that $\mathrm{N}_{2}$ carrier gas is more convenient than $\mathrm{O}_{2}$ at low temperatures $\left(\mathrm{T}<700^{\circ} \mathrm{C}\right)$ for two reasons: $\mathrm{O} / \mathrm{Ta}$ ratio is close to 2.5 and carbon content is low. The use of $\mathrm{O}_{2}$ as carrier gas increases the $\mathrm{O} / \mathrm{Ta}$ ratio and the carbon content, probably related to the formation of Ta-C-O compound [9]. On the other hand, at high temperatures $\left(\mathrm{T}>700^{\circ} \mathrm{C}\right)$, the presence of $\mathrm{O}_{2}$ during the deposition is necessary : a strong incorporation of carbon is observed at $800^{\circ} \mathrm{C}$ when $\mathrm{N}_{2}$ is used as carrier gas, due to the cracking of hexane. This phenomenon is more pronounced with the use of decane as solvent : X-ray pattern of a film deposited at $800^{\circ} \mathrm{C}$ under $\mathrm{N}_{2}$ reveals the presence of tantalum carbide.

\subsection{Multilayer of $\mathrm{Ta}_{2} \mathrm{O}_{5} / \mathrm{SiO}_{2}$}

This new process offers the possibility to connect several injectors to the evaporator, so composite films or multilayer films can be easily produced. In this part, we will show preliminary results about $\mathrm{Ta}_{2} \mathrm{O}_{5}$ ! $\mathrm{SiO}_{2}$ multilayers deposited by injecting a solution of hexane $+\mathrm{HDPM}$ with $\mathrm{Ta}(\mathrm{OEt})_{5}$ and $\mathrm{Si}(\mathrm{OEt})_{4}$ alternatively. Each injection sequence is 120 seconds apart. The concentration of the precursors were respectively 30 and $300 \mathrm{mg} / \mathrm{ml}$. Deposition was performed at $850^{\circ} \mathrm{C}$ under $50 \mathrm{sccm}$ of oxygen. This high deposition temperature was imposed by the high decomposition temperature of $\mathrm{Si}(\mathrm{OEt})_{4}$.

Whereas TEM requires a preparation of the sample, the important difference between atomic weight of Si and Ta allows to distinguish the monolayers by SEM, if their thickness is higher than $20 \mathrm{~nm}$. The lighted areas represent $\mathrm{Ta}_{2} \mathrm{O}_{5}$ on fig 10 . The thicknesses of the layer is around $30 \mathrm{~nm}$ for $\mathrm{Ta}_{2} \mathrm{O}_{5}$ and $50 \mathrm{~nm}$ for $\mathrm{SiO}_{2}$. The surface roughness is less pronounced than that of thick layers obtained at the same deposition temperature (fig 7). The width of X-ray diffraction lines (fig 11) suggests a small grain size. Reducing thickness of $\mathrm{Ta}_{2} \mathrm{O}_{5}$ monolayers should improve again the surface roughness. Further investigations have to be undertaken, particularly the study of the interfaces. 


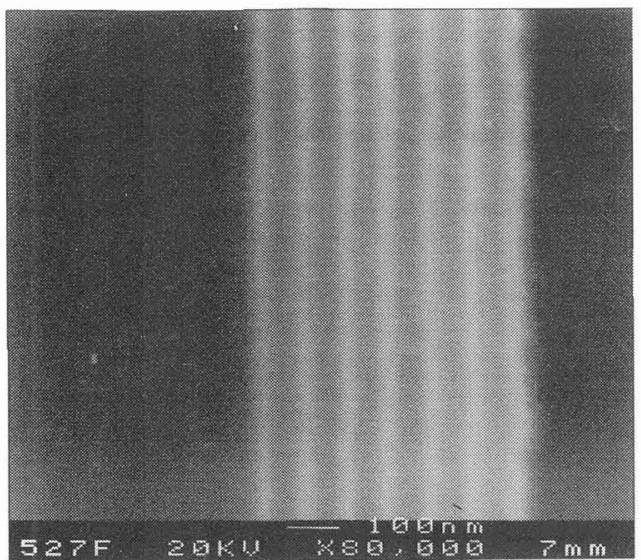

Figure 10: View of a cross-section of a multilayer $\mathrm{Ta}_{2} \mathrm{O}_{5} / \mathrm{SiO}_{2}$ deposited at $850^{\circ} \mathrm{C}$.

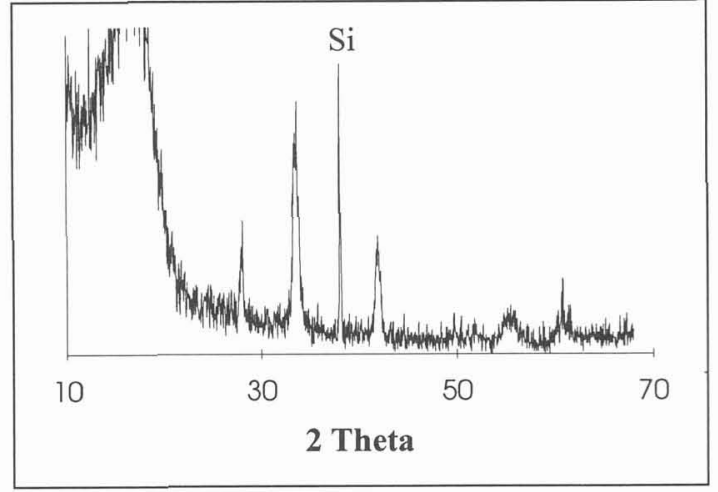

Figure 11: X-ray pattern of the multilayer. $\left(\lambda_{\mathrm{cu}}=0.15406 \mathrm{~nm}\right)$

\section{CONCLUSIONS}

A new MOCVD process has been presented for producing good quality thin layers. The results presented here demonstrate the feasibility of the sequential introduction of well controlled micro amount of precursors in CVD process, giving rise to a large scale of applications. This technique offers also several advantages like very high growth rates $\left(11 \mu \mathrm{m} / \mathrm{h}\right.$ for $\left.\mathrm{Ta}_{2} \mathrm{O}_{5}\right)$ and high versatility.

Our results are summarized as follows:

1- As-deposited $\mathrm{Ta}_{2} \mathrm{O}_{5}$ films are amorphous up to a deposition temperature of $650^{\circ} \mathrm{C}$ and present high refractive index and smooth surface.

2- Polycrystalline films deposited at high temperature $\left(850^{\circ} \mathrm{C}\right)$ have a maximum roughness of about $50 \mathrm{~nm}$ depth.

3- The annealing of amorphous films leads to polycrystalline films with a smooth surface and refractive index equivalent to the value of bulk material.

4- Stoichiometry and Carbon content depend on the gas nature. A surprising result is that the best stoichiometry is obtained with $\mathrm{N}_{2}$ (or $\mathrm{H}_{2}$ ) as carrier gas (lowest carbon content) at low temperatures.

5- The deposition of $\mathrm{Ta}_{2} \mathrm{O}_{5} / \mathrm{SiO}_{2}$ multilayer is easily obtained. The high flexibility of the computer, which enables the driving of many injectors, gives the possibility of growing very complex multilayered structures in a single run.

6- The source is a compact, hermetically sealed device, composed by the injector and the tank containing the precursors under inert gas. It needs only to be connected to the computer, the pressurized inert gas line and the evaporator and can be easily changed. This leads to a very high versatility for this kind of CVD reactor.

The suppression of hot lines and valves between the evaporator and the reaction zone substantially simplifies the reactor's design. The synthesis of layers composed by many chemical elements can be achieved either with a single source or with one injector per chemical element, which enables a computer controlled stoichiometry (for composition gradients for instance). The accuracy of the standard injectors actually produced is better than 3\% volume spread per injection (Bosch specification). The accuracy and reproducibility of the injectors, which are produced in large scale for motor car industry, is increasing rapidly, in relation with this highly competitive market.

The use of many injectors connected to the same evaporator opens the possibility of very simple layer-by-layer CVD deposition, which is a rather complex problem when a standard CVD device is used [2]. The presence of the solvent in the reaction zone, which can be a handicap or an improvement $[10,11]$, can be easily suppressed using mechanical transport of the precursor $[1,3]$ combined with the injection principle described here. These experiments are actually in progress in our laboratory. 


\section{Acknowledgements}

The authors are grateful to the CNET (Telecommunications Research Center) for support in characterization (RBS/NRA analysis and ellipsometry measurements). We would also like to thank J.Garden for the SEM photographies.

\section{References}

[1] Kaul A.R. and Seleznev B.V., Journal de Physique IV, 3, (1993), 375-378.

[2] Fujii K., Zama H. and Oda S., Jpn. j. Appl. Phys, 31, (1992), L 787-789.

[3] Klippe L., Stolle R., Decker W., Nurnberg A., Wahl G., Gorbenko O. YU., Erokhin Y., Graboy I.E., Kaul A.R. and Podziguin S.A, Proceedings of the First European Conf. on Appl. Superconductivity, H.C. Freyhart Ed., DMG Informationgesellschaft, Adenauerallee 21, D-61440 Oberusel Germany (1993).

[4] Weiss F., Frohlich K., Haase R., Labeau M., Sénateur J.P., Selbmann D, Journal de Physique IV, 3,(1993),321-327.

[5] Hiskes R., Di Carolis S.A., Jacowitz R.D., Lu Z., J. Cryst. Growth, 128, (1993), 781.

[6] Tominaga K., Muhammet R., Kobayashi I., Okada M., Jpn.Appl.Phys, 31, (1992), L585-587

[7] Treichel H., Mitwalsky A., Sandler N.P., Tribula D., Kern W., Lane A.P., Advanced Materials for Optics and Electronics, 2, (1993)

[8] Sun-Oo K., Hyeong Joon K., Thin Solid Films, 253, (1994), 435-439.

[9] Goldschmidt H.J., Interstitial alloys (Butterworth, 1967), 564.

[10] Matsuno S., Uchiawa F., Yoshizki K., Jpn. J. Appl. Phys., 29, (1990), L947.

[11] Aoki S., Yamaguchi T., Iijima Y., Kohno O., Nagaya S. and Inoue T., IEE Transaction on applied superconductivity, 3, n¹ (1993), 1691-1694. 